\title{
Information Management in Science and Technology
}

\author{
A.T. Francis \\ Kerala Agricultural University \\ francisaloor@yahoo.com
}

\section{INFORMATION}

The modern world has witnessed with an explosive nature of research and development activities in all fields of life. This in turn has created a phenomenon of knowledge explosion and consequent information explosion. The huge volume of information thus generated has raised several problems in its selection, processing, storage, retrieval and dissemination. Researchers, information specialists and technocrats have made continuous efforts to develop technologies, methods and processes to tackle the problems and achieve universal control on information.

In this context, it is better to familiarize the terms, "data", "information" and "knowledge".

i. Data is an undifferentiated observation of facts in terms of words, nos., symbols, etc. Eg. Scientific data, social data, trade statistics, etc.

ii. Information is the processed data and made it ready for communication. Eg. Analysis of population data, weather forecasting, etc.

iii. Knowledge is consolidated and structured information - understanding and skills acquired intuition, etc.

The Library and Information Systems are mainly concerned with the resource, "Information" and which forms the basis for all technological, engineering, academic and research activities. The activities of the advanced nations of the world are highly information oriented and hence, these societies are known as "Information Societies". We could see that the whole world is being controlled now by these information societies. Hence, all nations are struggling to acquire, control, disseminate and utilize information to the maximum extend possible.

\section{VALUE OF INFORMATION}

Accurate, timely, and relevant information saves both time and money through increased efficiency, improved productivity, and rapid deployment of innovations. For example, access to research results allows agencies to benefit from the experiences of others and avoids costly duplication of effort. While the benefits are substantial, they are difficult to quantify and the value of information goes unrecognized. Access to information yields both time and cost savings by improving decision making, expediting solutions, and avoiding unnecessary research. The direct benefit of information in academic field is the enhancement of quality of education. That is why the Radhakrishnan Commission on education has described the centre of information, that is, Library, as the heart of any educational institution. 
The information, whether nascent or archival, is available in different types of sources. These sources also may be called as information documents. These documents can basically be grouped according to:

i. Inner Form or Content; and

ii. Physical Form

Information sources may be in different inner forms as follows:

1. Primary sources:- It is any piece of information that is used for constructing history as an artifact of its times. These are documents contain first hand information. presents material from a first-hand witness to a phenomenon

Eg: Primary Journals, Patents, Theses, Standards, Reports, etc.

2. Secondary sources:- These are texts based on primary sources, and involve generalization, analysis, synthesis, interpretation, or evaluation. In the study of history, secondary sources are those writings which were not penned contemporaneously with the events in question. A secondary source is often a commentary or analysis of a primary source. These are the carriers of reprocessed information.

Eg: Abstracting and Indexing Journals, etc.

3. Tertiary sources:- Tertiary source is a selection and compilation of primary and secondary sources. Typical instances of tertiary sources are bibliographies, library catalogs, directories, reading lists and survey articles. Encyclopaedias and textbooks are examples of materials that typically embrace both secondary and tertiary sources.

Information sources may be in different physical forms such as palm leaf, papyrus (an early form of paper made from the pith of the papyrus plant, Cyperus papyrus), paper, microfilm, microfiche, CD-ROM. DVD, BD, Hyper CD-ROM, Web document, Online Journals and Databases, etc.

In the present context, the physical forms of documents may be grouped into:

1. Print Media; and

2. Electronic Media

\section{INFORMATION AVAILABILITY}

The availability and accessibility of Information has become much more complicated and complex now. The modern Information and Communication Technologies (ICT) have offered enormous opportunity for the management of information. Though, systematic approach and enough expertise are essential to achieve better control on information. A 
simple search on the Web during the month of Novermebr 2007 retrieved the references on the following topics as given below:

$\begin{array}{llll}\text { Engineering } & : & 273,000,000 & (27.3 \text { crores }) \\ \text { Civil Engineering } & : & 119,000,000 & (11.9 \text { crores }) \\ \text { Mechanical Engineering } & : & 111,000,000 & (11.1 \text { crores }) \\ \text { Electrical Engineering } & : & 136,000,000 & (13.6 \text { crores }) \\ \text { Computer Engineering } & : & 342,000,000 & (34.2 \text { crores }) \\ \text { Agriculture } & : & 157,000,000 & (15.7 \text { crores }) \\ \text { Medicine } & : & 299,000,000 & (29.9 \text { crores }) \\ \text { Law } & : & 455,000,000 & (45.5 \text { crores }) \\ \text { Rice } & : & 93,300,000 & (9.3 \text { Crores })\end{array}$

The number of Registered Websites as on April 2007 was 113,658,468 (11 crores). An increase of 32 lakhs Websites was recorded from the previous month's survey. Out of the total Websites, around 50 million (5 crores) sites were "active". It was estimated that the projection for the number of Websites as 2 billion by the year 2011.

\section{INFORMATION USERS}

Information users are forming part of many groups such as academicians, engineers and technocrats, medical and legal practitioners, planners, government officials, business people, agriculturists, general public, etc. They are involved in a variety of specialised and busy activities and at the same time many of them are not having enough expertise to access and manage essential information of the required quality and quantity in the required time frame.

As the users are facing problems in searching and analyzing the high volume of information generated, another group of personnel have emerged as Information Intermediaries. They should have background knowledge on the subject and expertise in information search. They serve as vital link between users and information and retrieve required information for the users.

\section{LIBRARY}

In the traditional sense of the word, a library is a collection of books and periodicals. This collection is often used by people who choose not to, or can not afford to, purchase an extensive collection themselves. However, with the collection or invention of media other than books for storing information, many libraries are now also repositories and access points for maps, prints or other artwork, microfilm, microfiche, audio tapes, CDs, video tapes and DVDs, and provide public facilities to access CD-ROM databases and the Internet.

Thus, modern libraries are increasingly being redefined as places to get unrestricted access to information in many formats and from many sources. More recently, libraries are understood as extending beyond the physical walls of a building, providing assistance in navigating and analyzing tremendous amounts of knowledge with a variety of digital tools.

\section{PROCESSING OF INFORMATION IN LIBRARIES}


Classification and cataloguing are the twin tools to process information documents in a library. Information or information documents are commonly classified according to their subject coverage. In a library, the information documents are arranged in a systematic order using any standard classification scheme available for the purpose.

Library Catalogue is a list of documents maintained in a library. It is a conventional Inforamtion Retrieval System. It may be a manual Card Catalogue or computerised. Entry or data in the catalogue identifies specifically each document in the library by Author, Title, Edition, Publisher, Accession Numbers, and Call Number. The Call Number is used to call a document from the library collection. MARC is the accronym for Mcachine Readable Catalogue, or computerised catalogue and OPAC is Online Public Access Catalogue.

\section{INFORMATION RETRIEVAL SYSTEMS (IRS)}

Information retrieval is the art and science of searching for information in documents, searching for documents themselves, searching for metadata which describe documents, or searching within databases, for text, sound, images or data. The term "information retrieval" was coined by Calvin Mooers in 1948-50. The IRS may be conventional or modern IT based. A Library Catalogue is a conventional IRS.

\section{INFORMATION TECHNOLOGY}

The advancement of Information Technology (IT) has helped to a great extend to solve many of the problems raised by the information explosion. The term IT is commonly used to mean a combination of computer and communication technologies used for the processing, storage, retrieval and dissemination of information.

According to the American Library Association (ALA) Glossary, "IT is the application of computers and other technologies to the acquisition, organization, storage, retrieval and dissemination of information". The IT is a generic term used for a group of technologies. The new technologies most relevant to the information retrieval systems are grouped as follows:

i. $\quad$ Computer technology;

ii. Communication technology; and

iii. Reprographic, micrographic and printing technologies

While the computer technology stresses on the processing aspect of information, the CDROM technology lays importance to its storage. The communication technologies such as telephone, cellular phone, Fax, Internet, E-Mail, teleconferencing, computer networking, online search, etc. are closely related to the dissemination aspect of information. The reprographic, micrographic and printing technologies are also associated to the dissemination of information.

\section{AUTOMATED IRS}

An Information Retrieval System (IRS) is a blend of: 
- Information; and

- Retrieval Techniques

For example; Books, Library Catalogues, Statement of Accounts, Package of Practices, etc. are conventional IRSs. A modern IRS makes use of the possibilities of Information Technology for information management and hence, it is a combination of "Information" and "Information Technology".

Automated information retrieval systems were originally used to manage information explosion in scientific literature in the last few decades. Many universities and public libraries use IR systems to provide access to books, journals, and other documents. IRSare often related to object and query. Queries are formal statements of information needs that are put to an IR system by the user. An object is an entity which keeps or stores information in a database. User queries are matched to documents stored in a database. A document is, therefore, a data object. Often the documents themselves are not kept or stored directly in the IRS but are instead represented in the system by document surrogates.

Web search engines such as Google, Yahoo, Lycos, etc. are amongst the most visible applications of information retrieval research.

\section{IT - AN ENABLER OF UNIVERSAL BIBLIOGRAPHICAL CONTROL}

Research activities are based on the existing and revealed stock of knowledge and hence, the researchers need full information about earlier findings. But, no library in the world is selfreliant. So, pooling and sharing of information resources is the only solution to achieve the Universal Bibliographical Control (UBC). Formation of regional or subject level networks and consortiums will help in this direction.

Developments of the IT in the following areas have made a quantum leap to achieve the UBC:-

- Processing speed - in khz to mhz, ghz, thz, etc.

- Storage techniques - in $\mathrm{kb}$ to $\mathrm{mb}, \mathrm{gb}$, tb, etc. and in medias like CD-ROM, CDR, DVD, BD, Hyper CD-ROM, etc.

- Bandwidth - Copper cable / Microwave channel to Optical Fibre Cable (OFC), WiFi, WiMax, High Speed Transponders, V-SAT (Very Small Aperture Terminal), Land phone to Cell Phone, Multimedia Phone, etc.

- Databases in CD, DVD, BD, Online, etc.

CD-ROM stands for Compact Disc - Read only Memory, popularly known as compact disc or CD. The CD-ROM technology is a system of recording or storing of digital information using laser technology on a metal / plastic disc. It is known as `Read Only Memory` because the information stored on a CD-ROM, cannot be erased or overwritten. The CD-ROM is a fastest growing storage and distribution technology, in the computer world.

The data are stored on small disc in the form of microscopic pits etched by laser beam. The compact disc has enormous capacity to store data. A single CD, $12 \mathrm{cms}$ in diameter and 1.2 
mm thick can accommodate $700 \mathrm{MB}$ of information, the equivalent of about 03 lakhs A4 typewritten pages of text or 500 high-density floppies. Now, the CD technology has been developed into re-writable CDs and DVDs (Digital Video Disk or Digital Versatile Disk). A single-sided DVD would contain 4.7 GB of information especially suited for feature-length movies. The double-layered discs will accommodate 8.5 GB and the dual-sided doublelayered disc $17 \mathrm{~GB}$.

\section{Blu-ray Disc and Hyper CD-ROM}

Blu-ray Disc (BD) is the name of a next-generation optical disc format jointly developed by the Blu-ray Disc Association (BDA), a group of the world's leading consumer electronics, personal computer and media manufacturers (including Apple, Dell, Hitachi, HP, JVC, LG, Mitsubishi, Panasonic, Pioneer, Philips, Samsung, Sharp, Sony, TDK and Thomson). The format was developed to enable recording, rewriting and playback of high-definition video (HD), as well as storing large amounts of data. A single-layer Blu-ray Disc can hold 25GB, which can be used to record over 2 hours of HDTV or more than 13 hours of standarddefinition TV. There are also dual-layer versions of the discs that can hold 50GB. The BD is expected to replace VCRs and DVD recorders with the transition to HDTV over the coming years. The format is also likely to become a standard for PC data storage and HD movies in the future.

The Hyper CD-ROM is a tridimensional multilayer optical memory, based on the phenomenon of controlled extinction of fluorescence. It allows the recording of information inside the "shelves" of a glass disk using laser beams. Such a glass disk has a storing capacity of over 10,000 Gigabytes (GB) of memory - an amazing size in comparison with those developed by the highest level computer firms and benchmarks - that allows storing of approximately 10 million books of standard format. It is in fact, an "optic tridimensional multilevel memory" so it can store data in over 10,000 different levels inside a glass disk 10 $\mathrm{mm}$ high and $120 \mathrm{~mm}$ in diameter. The most attractive aspect is that the support for storage (i.e. fluorescent photosensitive glass) is a very stable in time medium (information can be read during all the life of the glass - estimated to at least 5,000 years). The estimated capacity of this disc is $10 \mathrm{~TB}$ extendable up to $100 \mathrm{~TB}$. The average data-transfer rate is $3 \mathrm{Mb} / \mathrm{s}$ and the thermic resistance is up to 550 degree Celsius. Since it has very high fiability it will be stable in time and the estimated life of the disc is about 5,000 years.

The support of the optical memory is a fluorescent photosensitive material specially designed for this application. The writing / reading of the memory is realized with a system formed by a disk drive having the size doubled compared to the usual disk drives of the desktops PC, which incorporates a confocal microscope.

\section{Online Databases}

Based on the mode of access, the database search can be categorized into; online search and offline search. In the online search, the users access remote databases instantly and search for or download or print the required information without disconnecting the database link. But, in the offline search, the search query / keywords / hints for search are passed by the user to the Database Administrator for getting the required information. The Database 
Administrator will do the search on behalf of the user and forward the retrieved information to the user as and when the search completes.

Earlier, when the speed of the computers were low for processing the queries instantly, it was technically and economically feasible to resort to offline search. Moreover, capacity of the communication infrastructure to transfer the retrieved information to the end user was also low. Now, the high speed computers, OFC / Satellite based broad band communication networks, etc. have made the online search a practical reality. This has resulted in the development of large number of online databases.

\section{INFORMATION SOURCES IN ENGINEERING}

Databases:- Several databases are published in engineering and related subjects in CD / Online. Few important databases are listed below:

ABI/INFORM: Indexes over 1,400 business and economics periodicals and provides 50\% full text articles.

ACM Digital Library: Full text journals and conference proceedings from the Association for Computing Machinery

CCD (ChemExper Chemical Directory): CCD is a free database of chemical compounds accessible over Internet. Its powerful search engine allows you to find a chemical by its molecular formula, IUPAC name, common name, CAS number, catalog number, substructure or physical characteristics via Internet.

COMPENDEX: Indexes about 5000 journals, conference proceedings and reports in all branches of engineering. Produced by Elsevier Engineering Information, Inc., USA. Coverage of database is 1970 to the present. File size is more than 7,552,027 citations as on May 2007.

Current Contents: ISI's online version of the well known Current Contents journals, is produced in the United States by the Institute for Scientific Information (ISI).

EBSCO: A set of 19 databases from Ebsco Publishing- mostly full-text periodical collections, with an emphasis on peer-reviewed journals. Major components are Academic Search Premier, with 3,956 full-text journals, and Business Source Premier, with 3,317 fulltext journals.

Emerald: Provides access to over a 100 fulltext journals published by MCB University Press. Topics covered include property and engineering.

IEE (Institution of Electrical Engineers) It was a British professional organisation for electronics, electrical, manufacturing and IT professionals. In 2006 it merged with the IIE to form the Institution of Engineering and Technology (IET). The IEE was founded in 1871 as the Society of Telegraph Engineers and before the merger was the largest 
professional engineering society in Europe with a worldwide membership of around 120,000 .

IEEE (Institute of Electrical and Electronics Engineers), USA, Full-text Journals, Abstracting Journals, Standards: About 1300 Nos.

IEEExplore: Full-text of all IEEE and IEE publications including journal articles, conference papers, and technical standards.

Ingenta: Offers access to nearly 6,000 electronic full-text titles and millions of articles from the world's leading scholarly and professional publications.

INSPEC: The Institution of Engineering and Technology (IET), UK is the producer of INSPEC. (The Database for Physics, Electronics and Computing) includes the three Science Abstracts print abstract journal publications: Physics Abstracts, Electrical and Electronics Abstracts, and Computer and Control Abstracts, which began publication in 1898, and two other technology areas: Information Technology for Business, Manufacturing, \& Production and Mechanical Engineering. More than 10,2 million citations are there as on April 2007 with Weekly additions of about 9,000 citations.

International Civil Engineering Abstracts - ICEA: Covers the major civil engineering subjects including: construction management, environmental, structural and hydraulic engineering from 150 of the world's best civil engineering journals.

Journal Citation Reports (JCR): Is a unique database for journal evaluation and comparison, using citation data drawn from over 8,400 scholarly and technical journals worldwide. Each annual database contains the previous year's publication data, accumulating and tabulating citation and article counts in order to answer some fundamental questions, such as: What journals are most frequently used? What journals have the highest impact? Etc

NTIS (free public access): NTIS - National Technical Information Service is the largest, central resource for US government-funded scientific, technical, engineering, and business related information currently available. It provides free searching of 450,000 abstracted publications and a portal to online purchasing.

Proquest: An online serials database of more than 8,500 titles of which 50\% is in full text in general science \& technology, engineering, social science, medical, news and business. All are accessible through the ProQuest interface and can be searched individually or simultaneously.

Referex: Comprises over fully searchable 300 texts in three subject collections: chemical, petrochemical and process engineering, mechanical and materials engineering, and electronics \& electrical engineering. Each collection includes handbooks of engineering fundamentals, titles focused on technique and practice, specialized scholarly monographs.

SAE Digital Library - Technical Papers: Provides online full-text access to more than 18,000 technical papers published by the Society of Automotive Engineers from 1998 to date. 
Incorporates the Global Mobility Database, comprising over 130,000 bibliographic citations and document summaries of books, standards, journal articles, conference papers, etc on mobility research worldwide

Science Direct: Contains the full text of 1800 Elsevier Science journals in the Engineering, Physical, Medical, Technical, and Social Sciences.

SciFinder Scholars: Chemical databases from CAS (Chemical Abstracts Service), including journals, patents, books, reviews, meeting abstracts, dissertations, conference proceedings and technical reports from 150 countries

Standards Databases on the Web (free public access): This is an annotated bibliography of standards databases from international organizations such as ISO (International Standards Organization), and major industrial countries such as America, Australia, Britain, Canada, Europe, German, Japan, Russia, as well as New Zealand and Singapore.

Web of Knowledge: Web of Knowledge is the web interface for ISI group of products including Web of Science, Journal Citation Reports and Current Contents. You must have a personalised login to Web of Knowledge if you wish to save searches from either of these databases -- especially if you wish to create an email alert.

\section{Institutional Sources in India:-}

(i). NISCAIR (National Institute of Science Communication \& Information Resources) is an establishment under the CSIR. The former INSDOC has merged with some other organization to form NISCAIR. The National Science Library is functioning in NISCAIR and this provides Inter Library Services to libraries and individuals.

NISCAIR publishes the following:

- NUCSSI (National Union Catalogue of Scientific Serials in India)

- INPAT (Indian Patent Database):- It is a bibliographic database that provides information on more than 53,000 patents granted in India from the year 1975 to present.

- ISA (Indian Science Abstracts). IAS is a semi-monthly abstracting journal which has been reporting scientific work done in India since 1965.

- Wealth of India. It is an encyclopaedic series on India's raw material resources of plants, animals and minerals, details their occurrence, distribution, description, composition, utilization and trade.

(ii). INFLIBNET Centre:- Information and Library Network (INFLIBNET) Centre is an autonomous Inter-University Centre of the University Grants Commission (UGC) of India. It is a major National Programme initiated by the UGC in 1991 with its Head Quarters at Gujarat University Campus, Ahmedabad. UGC-INFONET is a reputed e-journals service provided to the universities. 
(iii). NCSI (National Centre for Science Information), IISc Campus, Bangalore

(iv). DELNET (Developing Library Network), JNU Campus, Delhi. It provides exhaustive inter library services.

\section{(v). National Programme on Technology Enhanced Learning (NPTEL)}

The National Programme on Technology Enhanced Learning is a joint venture of seven Indian Institute of Technologies (IIT) and Indian Institute of Science (IISc) to provide study materials in engineering sciences and technology. This project has formally launched in September 2006 and is funded by Department of Secondary and Higher Education, the Ministry of Human Resources Development, Government of India.

The main objective of NPTEL is to enhance the quality of engineering education in the country by developing curriculum based video and web courses. This is being carried out by IITs, IISc and other premier institutions as a collaborative project. The project is evolving and it is intended to provide learning materials, digitally taped classroom lectures, supplementary materials and links to state-of-the art research materials in every subject possible. Currently samples from approximately 70 courses offered by faculty in various departments and to students at all levels (B.Tech, M.Tech, M.S., M.Sc., Ph.D.) are given here. Approximately 140 courses are in various stages of preparation and distribution through internet.

All the faculty members are personally involved in the making of their respective courses in the electronic form. The purpose is to supplement classroom lectures. Discussion forums for each web course are available and that can be accessed through login. Web address is http:// www.nptel.iitm.ac.in/.

\section{CONCLUSION}

Knowledge Management is an important ability that to be inculcated in all teachers, students, scientists, technocrats, etc. in modern world. In this context, the academic institutions should focus attention to impart enough Information Literacy Skills to the concerned.

\section{REFERENCES:-}

1. ACRL (Association of College and Research Libraries) (2000). Information literacy competency standards for higher education. Chicago: Association of College and Research Libraries. http://www.ala.org/acrl/ilcomstan.html. (Accessed on 25-12-2006).

2. ALA (American Library Association (2000). The Information Literacy Competency Standards for Higher Education http://www.ala.org/ala/acrl/acrlstandards/ standards.pdf.

3. All India Council for Technical Education (AICTE). http://www.aicte.ernet.in/AboutAICTE.htm. (Accessed on 15-03-2006).

4. Bargellini, Maria Laura and Bordoni, Luciana (2001). The role of the library in a new learning scenario. Electronic Library. 19(3), 153-157. 
5. Billington, James H. (2006). UNESCO and US Library of Congress meeting on World Digital Library Project. (01-12-2006, Paris). http://www.loc.gov/about/ welcome/ speeches/wdl/wdl_6-6-05.html (Accessed on 05-12-2006).

6. Branin, J.J., D'Elia, G. and Lund, D. (1993). Integrated information services in an academic setting: the organizational and technical challenge. Library Hi Tech. 44(4), 75-83.

7. Byres, Fred R. (2003). Care and handling of CDs and DVDs: a guide for librarians and archivists. Washington: Council on Library and Information Resources, National Institute of Standards and Technology, USA, $42 \mathrm{p}$.

8. Casey, Michael E. and Savastinuk, Laura C. (2006). Library 2.0: Service for the next-generation library. Library Journal. 9/1/2006. http://www.libraryjournal.com/article/CA6365200.html (Accessed on 17-062006).

9. Chen, Derek H.C. and Dahlman, Carl J. (2004). Knowledge and Development: a cross-section approach, Washington: World Bank, 88p. http://wwwwds.worldbank.org/servlet/WDSContentServer/ WDSP/ IB/2004/08/31/ 000009486_20040831091103/ Rendered/ PDF/wps3366knowledge.pdf (Accessed on 20-10-2006).

10. Chen, Derek H.C. and Kee, Hiau Looi (2005). A Model on Knowledge and Endogenous Growth. World Bank Policy Research Working Paper No. 3539. Washington: World Bank. http://www-wds.worldbank.org/ external/ default/ WDSContentServer/IW3P/IB/2005/03/17/000112742_20050317091850/Render ed/INDEX/wps3539.txt (Accessed on 20-06-2007).

11. Colaric, Susan M. (2003). Instruction for Web Searching: an empirical study. College \& Research Libraries. March 2003, 111-122.

12. Council on Library and Information Resources (2005). Library as place: rethinking roles, rethinking space. Washington, D.C.: CLIR, 81p. http://www.clir.org/ pubs/abstract/pub129abst.html. (Accessed on 18-04-2006).

13. Drucker, Peter F. (1994). Knowledge Work and Knowledge Society: the social transformations of this century. The 1994 Edwin L. Godkin Lecture. Harvard University's John F. Kennedy School of Government on May 4, 1994. http://books.google.com/ books?id= kDuEFn2hSw4C\&pg= PA146\&lpg= PA124\&dq=Drucker+(1994).+Knowledge+Work+and+Knowledge+Society: +the+social+transformations+of+this+century.+The+1994+Edwin+L.

+ Godkin+Lecture\&ie $=$ ISO-8859-1\&output=html\&sig= iyjZllZrAUKAwxwZbopc8c2S6lc (Accessed on 15-05-2006).

14. Dubey, Yogendra P. (2003). New challenges in information management and elearning in the age of globalization: issues and opportunities. Library Herald. 41(2), 81-89.

15. Eden, B. and Bierman, K.J. (2002). Knowledge Access Management at Lied Library: cataloguing and Web site re-engineering. Library HiTech. 20(1), 90103.

16. Francis, A.T. (2005). Library consortia model for country wide access of electronic journals and databases. In Multilingual computing and information management in networked digital environment, Third International Convention on Automation of Libraries in Education and Research Institutions (CALIBER), Kochi, February 2-4, 2005, Proceedings, edited by T.A.V. Murthy et al. Ahmedabad: Inflibnet Centre/UGC, 497-504. 
17. Francis, A.T., Razak, Abdul C. and Kabir, Humayoon. (2006). Role of Information Professionals as Teachers and Trainers in Agricultural Education: an experience of the Kerala Agricultural University, India. In Preparing Information Professionals for Leadership in the New Age: Asia-Pacific Conference on Library and Information Education and Practice (A-LIEP), Singapore, April 3-6, 2006, Proceedings, edited by C. Khoo, D. Singh and A.S. Chaudhry. Singapore: School of Communication \& Information, Nanyang Technological University, 642-644.

18. Freeman, Geoffrey T. (2005). The Library as Place: changes in learning patterns, collections, technology, and use. In. Library as Place: Rethinking Roles, Rethinking Space. Council on Library and Information Resources Washington, D.C. pp. 1-9. http://www.clir.org/pubs/ abstract/ pub129abst.html. (Accessed on 13-11-2006).

19. Grassian, E.S. and Kaplowitz, J.R. (2001). Information Literacy Instruction: theory and practice. ISBN 1-555-70406-9. New York: Neal-Schuman Publishers, Inc. $468 \mathrm{p}$.

20. IFLA/UNESCO (2006). IFLA/UNESCO Internet Manifesto Guidelines: September 2006. http://www.ifla.org/faife/ policy/ iflastat/InternetManifestoGuidelines.pdf. (Accessed on 11-07-2007).

21. India. University Education Commission, 1948-49. Report. Delhi, Manager of Publications, 1949, 2 Vol. (Chairman: S. Radhakrishnan), 110.

22. ITU and UNCTAD (International Telecommunication Union and United Nations Conference on Trade and Development) (2007). World Information Society Report 2007. Geneva: ITU. 207p. http://www.itu.int/wisr. (Accessed on 12-072007)

23. Kalam, A.P.J. Abdul (2006). World Knowledge Platform: a speech, at the IBM Investors Meet at Bangalore on June 2006. http://www.ciol.com/content/developer/newsmakers/2006/106060701.asp? nl=3_181844_Jun8. (Accessed on 12-06-2006).

24. Kaur, Amritpal (2000). Five Laws: their relevance in Information Technology environment. ILA Bulletin. 2000(1), 24-27.

25. Krishan Kumar (2000). Library Manual, New Delhi: Vikas Publishing House, 386p.

26. Longue, Susan (2003). The Changing Role of Libraries in Instructional Support. Information Technology and Libraries. 22(2). http://www.lita.org/ala/lita/litapublications/ital/2202editorial.cfm (Accessed on 18-03-2007).

27. Mittal, Savitha (2005). Digital library resources. New Delhi: Ess Ess Publications. 282p.

28. NAAC (National Assessment and Accreditation Council), India (2006). Library and information services: case presentations. Best Practice Series. Bangalore: NAAC. $79 \mathrm{p}$.

29. NPTEL (National Programme on Technology Enhanced Learning) (2006), India: Joint venture of IITs and IISc to provide study materials in engineering sciences and technology. http://nptel.iitm.ac.in/. (Accessed on 22-09-2006).

30. OCLC (2006). Students' Perceptions of Libraries and Information Resources: a Report to the OCLC Membership. A companion piece to perceptions of libraries and information resources. http://www.oclc.org/ reports/2005perceptions.htm (Accessed on 18-12-2006). 
31. Oladokun, Olugbade Samuel (2006). The Networked World of Lifelong Learning and the Challenging Role of the Library. Information Development. 22(2), 102109.

32. Pawinun, Prapat, Nyamboga, Constantine and Kemparaju, T.D. (2001). Information literate users and the Digital Society. In Digital Libraries: dynamic landscapes for knowledge creation, access and management. The Fourth International Conference of Asian Digital Libraries (ICADL), Bangalore, December 10-12, 2001, Conference Papers, edited by Shalini R. Urs, T.B. Rajashekar and K.S. Raghavan. Bangalore: University of Mysore and Indian Institute of Technology, 231-246.

33. Ranganathan, S.R. (1940). Reference service and bibliography, v. 1, Madras, Madras Library Association, 1940, 25p. (Source: Library manual; Krishan Kumar. Vikas Publications).

34. Ranganathan, S.R. (1957). Five laws of Library Science, $2^{\text {nd }}$ ed. Reprint in 1988. Bangalore: Sarada Ranganathan Endowment for Library Science, 449p.

35. UGC (1959). Report of the Library Committee, 1959. New Delhi: UGC, 228 p.

The Author:-

Dr. A.T. Francis

Head, Library; and I.T. Nodal Officer

College of Horticulture

Kerala Agricultural University

Thrissur - 680 656, Kerala, India

E-mail: francisaloor@yahoo.com

(o) 91-487-2370822-extn: 307; ® 91-487-2375816 (m) 91-9496839409 